\title{
Rottlerin-induced autophagy leads to the apoptosis in breast cancer stem cells: molecular mechanisms
}

\author{
Dhruv Kumar ${ }^{1}$, Sharmila Shankar ${ }^{2}$ and Rakesh K Srivastava ${ }^{1 *}$
}

\begin{abstract}
Background: Autophagy is an indispensable lysosomal self-digestion process involved in the degradation of aggregated proteins and damaged organelles. Autophagy is associated with the several pathological processes, including cancer. Cancer stem cells (CSCs) play significant roles in cancer initiation, progression and drug resistance. Recent studies have demonstrated the antitumor activities of plant-derived chemopreventive agent rottlerin (Rott). However, the molecular mechanism by which Rott induces autophagy in breast CSCs has not been investigated.

Results: The objectives of this study were to examine the molecular mechanism by which Rott induces autophagy which leads to apoptosis in breast CSCs. Treatment of breast CSCs with Rott for $24 \mathrm{~h}$ resulted in a concentration dependent induction of autophagy, followed by apoptosis as measured by flow cytometry. Electron microscopy confirmed the presence of autophagosomes in Rott treated breast CSCs. Western blot analysis showed that Rott treatment increased the expression of LC3, Beclin-1 and Atg 12 that are accumulated during autophagy. Prolonged exposure of breast CSCs to Rott caused apoptosis which was associated with the suppression of phosphorylated Akt and mTOR, upregulation of phosphorylated AMPK, and downregulation of anti-apoptosis BCl-2, BCl- $X_{L}$, XIAP and CIAP-1. Knock-down of Atg7 or Beclin-1 by shRNA inhibited Rott-induced autophagy at $24 \mathrm{~h}$. Our study also demonstrates that pre-treatment of breast CSCs with autophagosome inhibitors 3-methyladenine and Bafilomycin, as well as protein synthesis inhibitor cycloheximide inhibited Rott-induced autophagy and apoptosis. Rott induces autophagy via extensive cytoplasmic vacuolization in breast CSCs. Molecular docking results between C2-domain of protein kinase C-delta and Rott indicated that both hydrogen bonding and hydrophobic interactions contributed significantly for ligand binding with minimum binding affinity of $\approx 7.5 \mathrm{Kcal} / \mathrm{mol}$. Although, autophagy inhibitors suppress the formation of cytoplasmic vacuolization and autophagy in breast CSCs, the potency of Rott to induce autophagy and apoptosis might be based on its capability to activate several pathways such as AMPK and proteasome inhibition.
\end{abstract}

Conclusions: A better understanding of the relationship between autophagy and apoptosis would eventually allow us to discover novel drugs for the treatment of breast cancer by eliminating CSCS.

Keywords: 3-methyladenine (3-MA), Autophagy, Bafilomycin (Baf), Beclin-1, Cycloheximide (CHX), LC3, AMPK, Atg12

\footnotetext{
* Correspondence: rsrivastava@kumc.edu

${ }^{1}$ Department of Pharmacology, Toxicology and Therapeutics, and Internal Medicine, The University of Kansas Medical Center, 3901 Rainbow Boulevard, Kansas City, KS 66160, USA

Full list of author information is available at the end of the article
}

\section{Biomed Central}

(c) 2013 Kumar et al.; licensee BioMed Central Ltd. This is an open access article distributed under the terms of the Creative Commons Attribution License (http://creativecommons.org/licenses/by/2.0), which permits unrestricted use, distribution, and reproduction in any medium, provided the original work is properly cited. 


\section{Background}

Autophagy is a highly conserved cellular process that is involved in several catabolic processes, cellular development [1], autoimmunity [2], degradation of long-lived proteins and organelles [3], and cell death [4]. It has also been involved in several other cellular mechanism which are directly or indirectly related to diseases like neurodegeneration, cardiovascular, aging and cancer [5]. Autophagy takes place at basal levels in most of the cell types but is also regulated developmentally and/or by environmental stimuli. Autophagy is upregulated when cells encounter environmental stressors such as nutrient starvation, pathogen infection and chemotherapeutic agents, [6-9] and the process is essential for the maintenance of cellular energy, and thereby, for cell survival in stress conditions [10,11]. Although autophagy is initiated as a protective response to stress, the constitutive activation of autophagy can lead to cell death by excessive self-degradation of essential cellular components [12].

Recently, it has been reported that the chemotherapeutic agents $[13,14]$ induced the early stage of autophagy in cancer stem cells (CSCs) $[15,16]$, and it is regulated by several 'Atg' (Autophagy-related) genes [17] and proteins which have been implicated in autophagosome formation [18]. Autophagosome nucleation requires a complex containing Atg6, whereas elongation of autophagosome involves Atg12 and Atg8 (LC3 in mammals) [19]. Atg7 is required to recruit other proteins to the autophagosomal membrane and to form the autophagic vacuole in a pathway $[20,21]$. All together, they form autophagic membrane; this membrane assembles around damaged organelles, proteins and cytoplasm. Later, the outer membrane of autophagosomes is fused by endosomes or lysosomes to form autolysosomes where lysosomal hydrolases degrade the cytoplasm derived contents of autophagosome together with its inner membrane and presented to citric acid cycle for energy generation [22]. Moreover, an important autophagy-regulatory gene such as Beclin-1 functions as a haplo-insufficient tumor suppressor gene [23], further emphasizing the clinical importance of autophagic cell death and apoptosis.

Despite of these advances, the relationship between autophagy and apoptosis in CSCs is still not well understood. CSCs may be responsible for tumor onset, self-renewal/ maintenance, mutation accumulation, and metastasis [24]. In CSCs, autophagy plays an important role in the regulation of drug resistance, self-renewal, differentiation, and tumorigenic potential $[25,26]$, suggesting autophagy could be a promising therapeutic target in a subset of cancers. In some circumstances, both autophagy and apoptosis have been observed in the same cells, [27-30] and they may be interconnected by some signaling pathway $[17,31]$. The Akt/mTOR and AMPK signaling pathway is a key regulator of physiological cell processes which include proliferation, differentiation, apoptosis, motility, metabolism, and autophagy. Several anti-apoptotic signals such as the Akt/mTOR signaling pathway, and Bcl-2 suppress autophagy $[17,32]$ and concurring-apoptotic signals such as the AMPK signaling pathway, and Bax activate autophagy [33]. Conversely, autophagy may inhibit apoptosis, [34,35] and the inhibition of autophagy can activate apoptosis $[28,31,36]$.

Autophagy also plays an essential role in the maintenance of cellular energy and for cell survival in stress conditions $[10,11]$. Endoplasmic Reticulum (ER) stress and activation of AMPK are among the major regulators of autophagy [37], which are involved in biosynthesis, protein folding and modification of various soluble and insoluble proteins [38]. The ER-resident proteins, PERK and IRE1, and increased cytosolic calcium have been implicated as mediators of ER stress induced autophagy in mammalian cells [39]. These mediators activate autophagy by upregulating Atg12 and LC3 conversion [40]. ER stress also leads to release of calcium from ER to cytosol, which in turn can activate various kinases that are involved in autophagy signaling [41,42]. Calcium mediated autophagy is regulated by AMP activated protein kinase (AMPK), which senses cellular energy status to maintain homeostasis. It is usually activated when ATP levels are depleted in the cells. Increase in the cytosolic calcium leads to the activation of $\mathrm{Ca} 2+/$ calmodulin activating kinase kinase $\beta$ (CAMKK $\beta)$ which further activates AMPK [43]. In addition, both AMPK and mTOR regulate autophagy through coordinated phoshphorylation of Ulk1 $[44,45]$. Thus activating autophagy may abolish the resistance of CSCs to chemotherapy and could lead to the development of novel therapeutic approaches for the treatment of various cancers.

Rott has been used as a protein kinase C-delta signaling pathway inhibitor [46]. It inhibits cell proliferation and induces apoptosis through mitochondrial membrane depolarization. Recently, in several human cancer cells, Rott has been shown to induce a starvation response, which is a key regulator of autophagy causing its induction [47]. We have recently reported the existence and role of human pancreatic CSCs in autophagy leading to apoptosis induced by Rott $[26,48]$. Since breast cancer contains rare breast CSCs, we sought to examine the molecular mechanism by which Rott induces autophagy in breast CSCs. Breast cancer is one of the leading gynecological cancers with high mortality rates. It is usually detected in late stages with poor prognosis. Here we report that Rott-induced early autophagy is mainly dependent on the induction of autophagosomes, conversion of LC3-I to LC3-II, expression of Atg12 and Beclin-1 and inhibition of Bcl-2, Bcl-xL, XIAP and cIAP-1. Eventually, Rott induced apoptosis through the inhibition of Akt/mTOR pathway, and activation of caspases and 
AMPK pathways. Moreover, expression of Atg12 and Beclin-1 enhanced apoptosis-inducing potential of Rott. These findings strongly suggest that Rott-induced autophagy may play some important role in induction of apoptosis. For the first time we report that Rott activates autophagy by inducing the phosphorylation of AMPK. We show a novel function of Rott that is involved in inducing early autophagy and late apoptosis in breast CSCs.

\section{Results}

Rottlerin induced cytoplasmic vacuolation and cell death in breast CSCs

To examine whether Rott induces cytotoxic effect on breast CSCs, we treated breast CSCs with different concentrations of Rott $(0,0.5,1$ and $2 \mu \mathrm{M})$ for various time points
$(12,24,48$ and $72 \mathrm{~h})$. Rott inhibited cell viability in a timeand dose-dependent manner (Figure 1a). While the treatment with $0.5 \mu \mathrm{M}$ Rott had little effect on cell viability, treatments with 1 or $2 \mu \mathrm{M}$ Rott for 48 and $72 \mathrm{~h}$ significantly inhibited cell viability. We next measured cytoplasmic vacuolation induced by Rott (Figure $1 \mathrm{~b}$ and $\mathrm{d}$ ). Rott induced autophagy in breast CSCs by forming cytoplasmic vacuolation in a dose-dependent manner. $1 \mu \mathrm{M}$ and $2 \mu \mathrm{M}$ Rott induced more cytoplasmic vacuolatyion in breast CSCs compared to $0.5 \mu \mathrm{M}$ (Figure $1 \mathrm{~b}$ and d). Whereas, cotreated breast CSCs with Rott and Baf, 3-MA or CHX inhibited cytoplasmic vacuolation (Figure $1 \mathrm{c}$ and e). Moreover, the breast CSCs treated with Rott showed morphological features of cytoplasmic vacuole accumulation. Rott increased more numbers of vacuole formation in the cytoplasm of breast CSCs (Figure 1d).

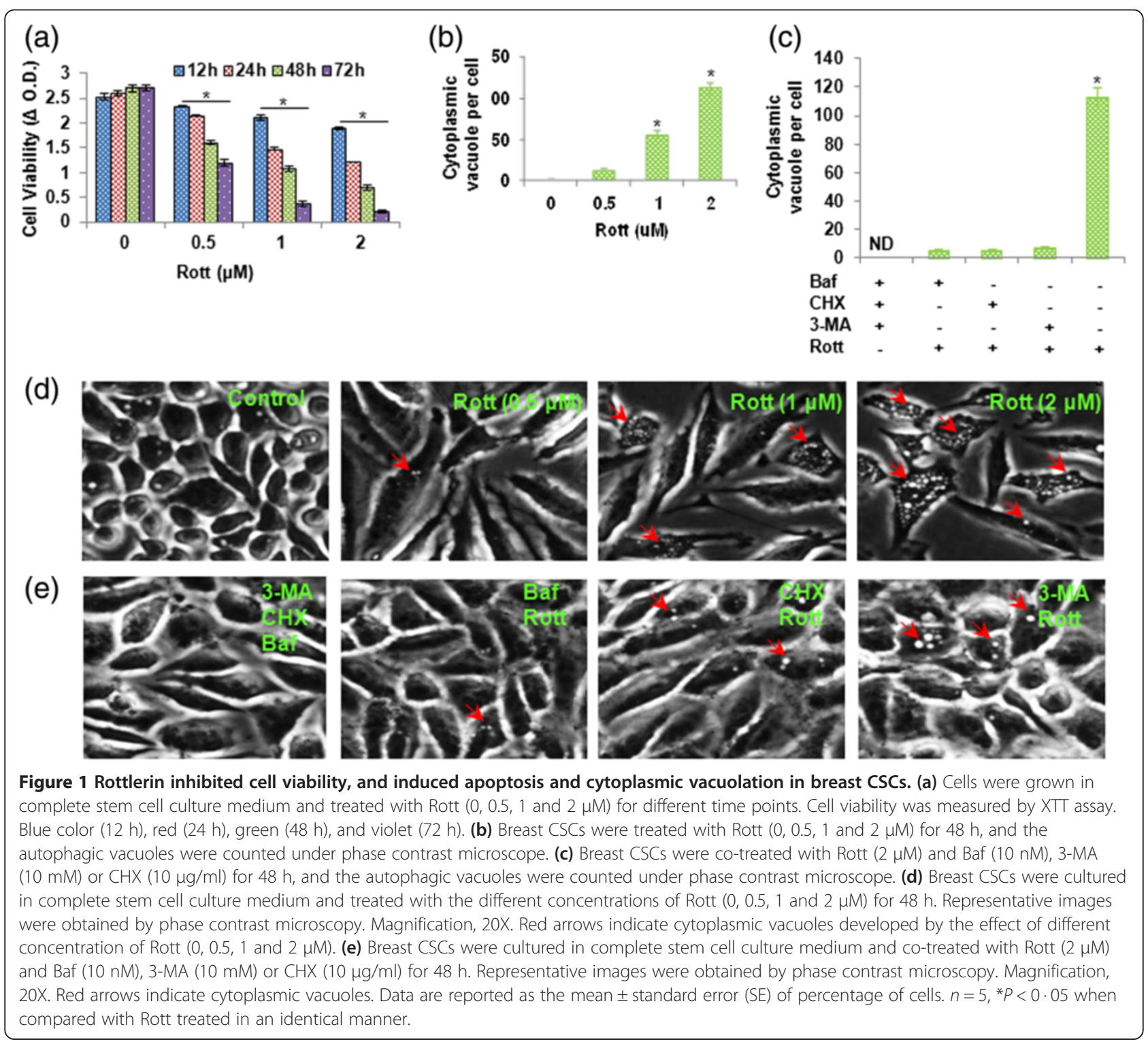


Rottlerin induced early stage autophagy in breast CSCs LC3 is a hallmark of autophagy and the conversion of LC3I to LC3-II via proteolytic cleavage and lipidation shows autophagy induction. Therefore, to study whether Rott induced autophagy in breast CSCs, the formation of LC3 punctate dots and conversion of LC3-I to LC3-II were examined by different molecular technique. This modification of LC3 is essential for the formation of autophagosomes and for the completion of macroautophagy. To confirm whether LC3 (autophagosomes) is redistributed after Rott treatment, we observed the induction of LC3 punctate dots in LC3 transfected breast CSCs with the exposure of different concentration of Rott (Figure 2a). Cells were cultured in complete stem cell culture medium, treated with or without Rott and subjected to immunofluorescence for visualization of pEGFP-LC3 transfected cells. Our results indicated that Rott induced autophagy in a dose dependent manner (Figure 2a). To examine whether cell vacuolation induced by Rott is related to autophagy, breast CSCs were treated with $\operatorname{Rott}(0,0.5,1$ and $2 \mu \mathrm{M})$

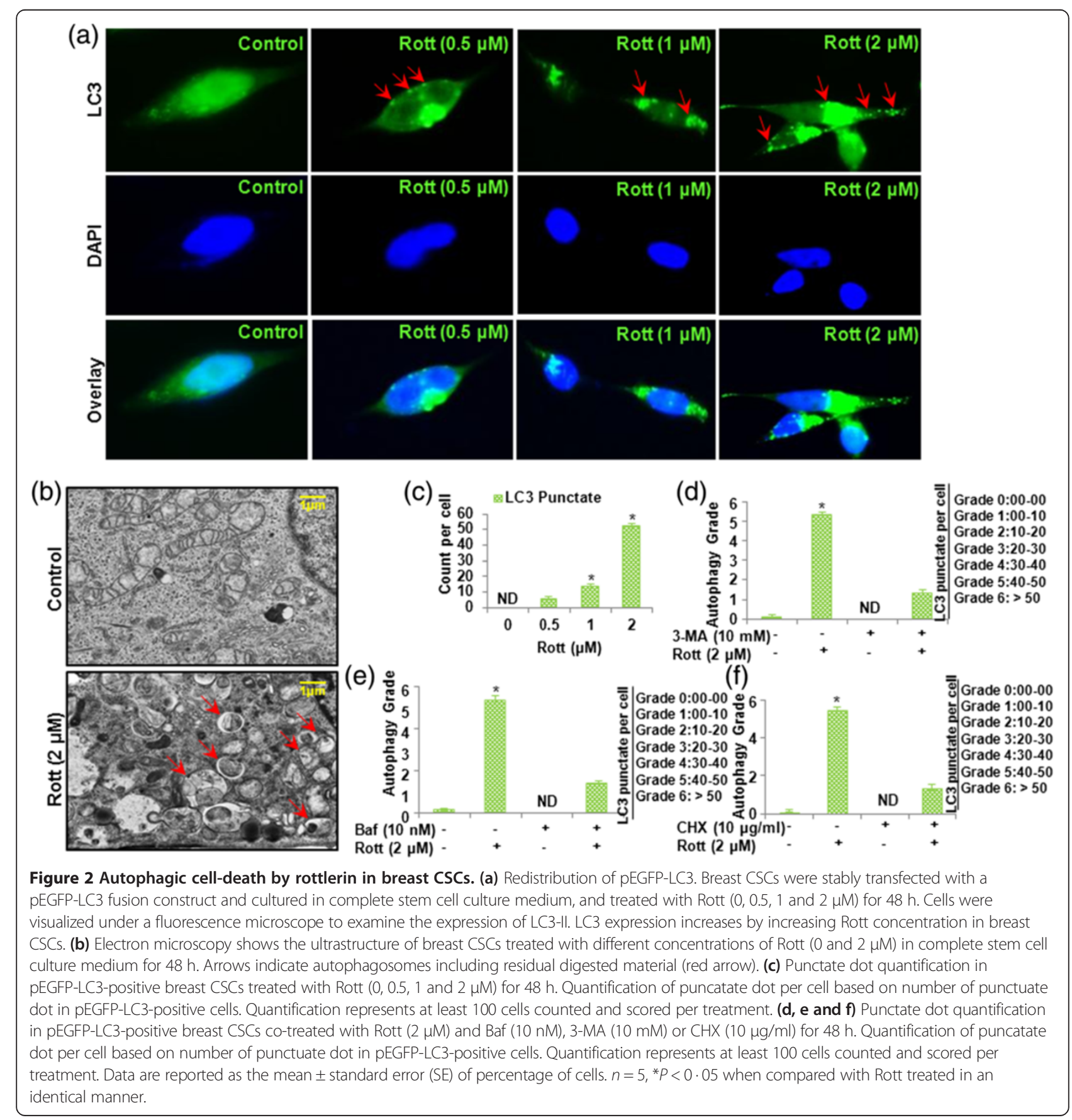


for $48 \mathrm{~h}$ and the ultrastructure of cells were analyzed by electron microscopy. Numerous autophagic vacuoles containing lamellar structures or residual digested material and empty vacuoles were observed in the breast CSCs when treated with $2 \mu \mathrm{M}$ of Rott, indicating that Rott not only increased the number of vacuoles, but also increased the number of mature autophagosomes formed per cell (Figure 2b). We next counted and graded CSCs based on abundance of LC3-II positive staining. The number of LC3-II positive CSCs and severity of autophagic response per cell (number of autophagosomes present per cell) was increased following Rott treatment at $48 \mathrm{~h}$ (Figure 2c).

However the co-treated breast CSCs with Rott and autophagy inhibitors Baf, 3-MA or CHX inhibited autophagy (Figure 2d, e and f). 3-MA is a phosphatidylinositol 3kinase class-III enzyme inhibitor which is essential for the autophagic process and the autophagy inducing potential of Rott was partially reverted with 3-MA, indicating that inhibition of phosphatidylinositol 3-kinase class III enzyme reduced the number of cells undergoing autophagy. Baf is a potent and specific inhibitor of vacuolar $\mathrm{H}+$ ATPase (VATPase) which stops the acidification of lysosomes during the formation of autophagosomes and slows down the lipidation of LC3 protein. CHX, a small molecule inhibitor of protein synthesis, blocks the elongation phase of eukaryotic translation.

\section{Molecular evidence of regulation of autophagy by rottlerin}

To determine whether Rott regulates autophagy at 24$48 \mathrm{~h}$, first we examined the levels of LC3-II, which is an LC3-phosphatidylethanolamine conjugate and a promising autophagosomal marker. Rott induced an increase in the lipidated form of LC3 (LC3-II) at 24-48 h, further indicating the induction of autophagy at early stage (Figure 3a). However, Rott-induced conversion of LC3-I to LC3-II was not observed at $72 \mathrm{~h}$. We next measured the expression of autophagy-related proteins, LC3, Atg12, Beclin-1 in breast CSCs treated with Rott (Figure 3b). The levels of Atg12 and Beclin-1 expression were increased in a dose dependent manner following treatment with Rott. These results indicate that Rott stimulated not only the conversion of a fraction of LC3-I into LC3-II but also caused the accumulation of Atg12 and Beclin-1 proteins. The cellular levels of Bcl-2, Bcl-xL, XIAP and cIAP-1 proteins were significantly decreased after the treatments with Rott for $48 \mathrm{~h}$ (Figure 4a). The accumulation of Atg12 and Beclin-1 proteins may be mediated by the reduction in $\mathrm{Bcl}-2$ and $\mathrm{Bcl}-\mathrm{xL}$ expression. To assess how the pro-apoptotic effect of Rott was linked to the autophagies signal, we used autophagy inhibitors (Baf and 3-MA), and protein synthesis inhibitor (CHX). Treatment of breast CSCs with Baf, 3-MA or CHX inhibited Rott-induced conversion of LC3, and induction of Atg12 and Beclin-1 (Figure 3c, d and e), suggesting that Rott has potential to induce autophagy in CSCs.
Inhibition of Atg7 or Beclin-1 by shRNA suppressed Rott-induced autophagy in breast CSCs. We have recently demonstrated the requirement of Atg7 or Beclin-1 in Rott-induced autophagy $[25,26]$. To investigate the mechanism of Rott-induced autophagy in breast CSCs, we inhibited autophagy by Atg7 shRNA or Beclin-1 shRNA. These plasmids have been previously validated in our laboratory [25,26]. As shown in (Figure 3f), overexpression of either Atg7 shRNA or Beclin-1 shRNA suppressed Rott-induced autophagy, suggesting the requirement of these genes in Rott-induced autophagy.

\section{Rottlerin-induced autophagy is mediated via activation of AMPK pathway}

Several recent studies have shown that activation of AMPK is important in regulating autophagy. We wanted to test whether this was the case in our model. The western blot data showed that Rott activated AMPK by phosphorylating it at Thr-172 in breast CSCs. Further, to confirm the role of AMPK in Rott induced autophagy, we exposed the CSCs to Baf, 3-MA or CHX before treating with Rott. Treatment of breast CSCs with Baf, 3MA, and CHX inhibited Rott-induced activation of AMPK (Figure 3c, $\mathrm{d}$ and e). Interestingly, blocking AMPK activation also blocked the expression of LC3, Atg12 and Beclin1 in breast CSCs, indicating that AMPK also mediates the effect of Rott on autophagy. These results strongly establish that AMPK is a major regulator of Rott-induced autophagy in breast CSCs.

\section{Rottlerin induced apoptotic cell death via inhibition of Akt/mTOR pathway and activation of caspases}

Akt/mTOR signaling pathway is involved in the regulation of cell cycle, cellular transformation, cell growth, and tumorigenesis. To investigate the upstream inhibition of mTOR by Rott, we examined Ser473 phosphorylation of Akt. As shown in (Figure 4b), treatment with Rott decreased the levels of phosphorylated Akt and mTOR in breast CSCs. These data suggest that Rott induces apoptosis by inhibiting Akt/mTOR pathway. To gain further insight into the mechanism by which Rott induces cell death, we examined the effects of Rott on the expression of apoptosis-related proteins (Figure 4a and b). Treatment of breast CSCs with Rott resulted in cleavage of caspase- 3 and caspase-9. Furthermore, the levels of IAP family proteins, such as XIAP and cIAP-1, which bind to caspases and lead to their inactivation, were downregulated by Rott treatment (Figure 4a). Moreover, the cellular levels of anti-apoptotic Bcl-2 and $\mathrm{Bcl}-\mathrm{xL}$ proteins were significantly decreased, whereas pro-apoptotic Bax level was increased in response to Rott, indicating Rott induced cell death in CSCs due to an increase in the relative ratio of $\mathrm{Bax} / \mathrm{Bcl}-2$ (and/or Bcl-xL) expression. 


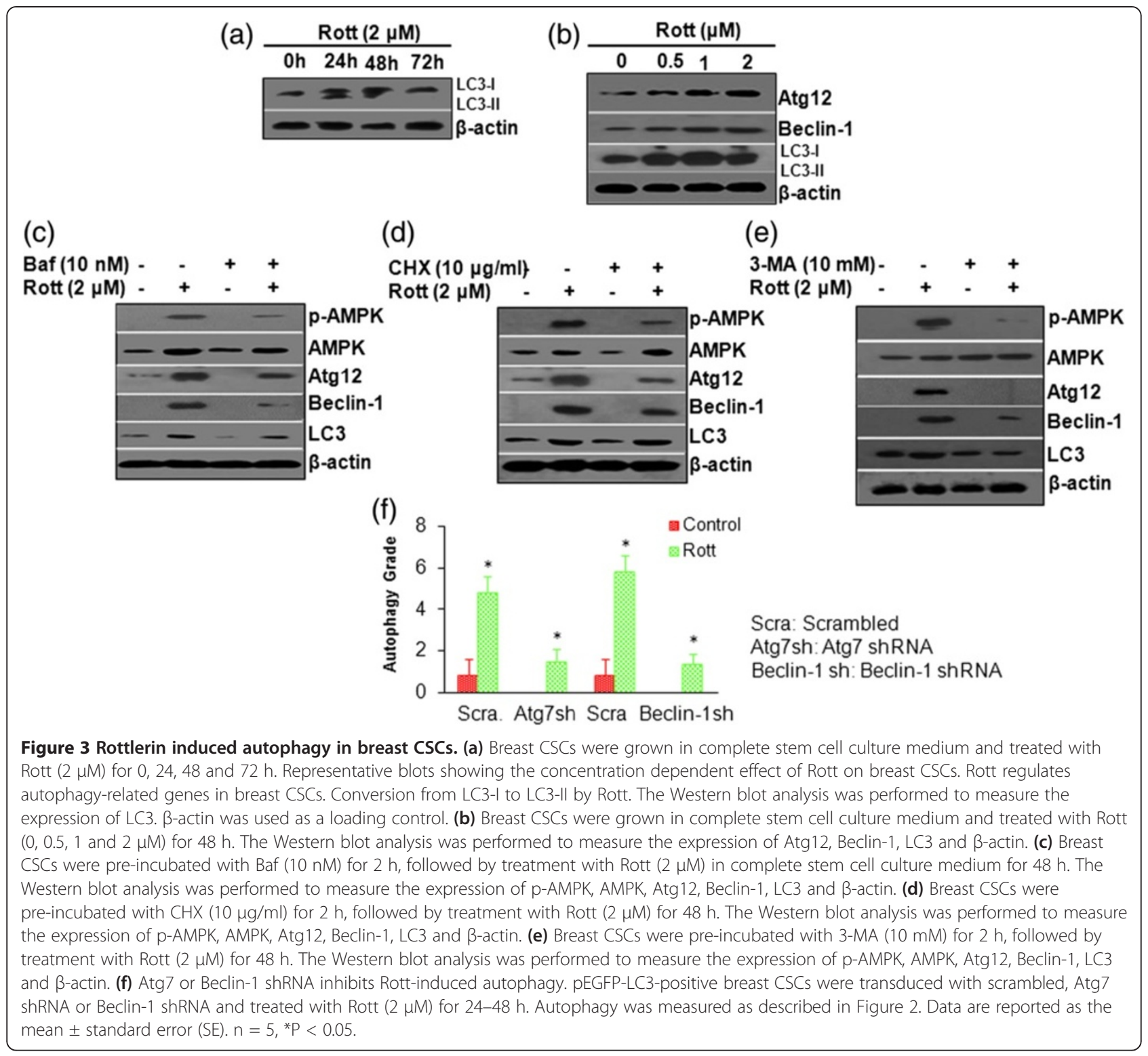

\section{Rottlerin induced apoptotic cell death in breast CSCs}

We studied the effect of Rott on the induction of autophagy leads to the apoptotic cell death in breast CSCs by using C6-flow cytometer. Rott did not significantly induce apoptosis in breast CSCs at 24 and $48 \mathrm{~h}$ (data not shown), but significantly induced apoptotic cell death at $72 \mathrm{~h}$ (Figure 5a to e). Breast CSCs treated with different concentration of Rott $(0,0.5,1$ and $2 \mu \mathrm{M})$ underwent apoptosis as assessed by flowcytomer using propidium iodide (PI), and annexinV/PI staining (Figure 5a, b, c, d and e). Cells underwent apoptosis quickly showed an increase in annexin- $\mathrm{V}$ binding by increasing Rott concentration but excluded PI (early apoptosis). At later time-points, the percentage of PIstaining of breast CSCs gradually increased (late apoptosis). Therefore, we report here both the percentage of early apoptosis (which indicates annexin- $\mathrm{V}$-positive cells only) and the percentage cell death, which indicates the total number of annexin-V-FITC-plus PI staining cells and is representative of populations containing cells at both early and late stages of apoptosis.

Further, to confirm the role of Baf, 3-MA or CHX in apoptotic cell death, we exposed breast CSCs to Baf, 3MA or CHX before treating with Rott. Rott-induced apoptosis in breast CSCs, as assessed by PI (Figure 6a, b, $c$ and d) and annexin-V/PI (Figure 7a, b, c, d and e) staining through flow cytometry. Pretreatment of CSCs with Baf, 3-MA or CHX inhibited Rott induced apoptosis. These data suggest that inhibition of autophagosome and protein synthesis can block Rott-induced apoptosis. 

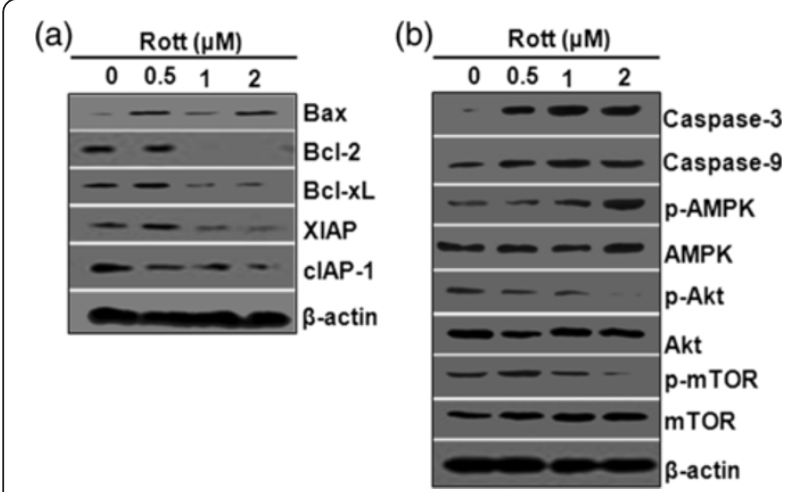

Figure 4 Rottlerin induced apoptosis in breast CSCs. (a) Breast CSCs were grown in complete stem cell culture medium and treated with Rott $(0,0.5,1$ and $2 \mu \mathrm{M})$ for $48 \mathrm{~h}$. The Western blot analysis was performed to measure the expression of $\mathrm{Bax}, \mathrm{BCl}-2$, $\mathrm{BCl}-\mathrm{xL}, \mathrm{XIAP}, \mathrm{CIAP}-1$, and $\beta$-actin. (b) Breast CSCs were grown in complete stem cell culture medium and treated with $\operatorname{Rott}(0,0.5,1$ and $2 \mu \mathrm{M}$ ) for $48 \mathrm{~h}$. The Western blot analysis was performed to measure the expression of active caspase-3, active caspase-9, p-AMPK, AMPK, p-Akt, Akt, p-mTOR, mTOR and $\beta$-actin.

\section{Molecular docking between C2-domain of protein kinase C-delta and rottlerin}

Molecular docking is a computational method that attempts to predict noncovalent binding between macromolecule (receptor/protein) and a small molecule (ligand). In order to understand the induction of autophagy in CSCs in exposure to Rott we have performed molecular docking between protein kinase C-delta inhibitor (Rott) [46] and C2-domain of protein kinase C-delta [49]. We have used AutoDock-Vina [50] docking program to see the interaction between protein and ligand. There are several other docking programs (e.g. GOLD, FleX, FRED) which can be used to predict the binding affinity between protein and ligand. AutoDock-Vina showed best for carrying out blind docking between protein and ligand among them [51]. Each docking result generated top ten best binding conformations of the ligand and the best binding poses (Figure 8 ). The 3D view of protein-ligand interactions of the best poses generated by ADT are shown in Figure 8. As clearly showed in Figure 8, an important interactions can be found between ligand and the residues SER8, ASN10, THR58, GLU83, PRO80, VAL84, THR85, GLN109, CYS117 and GLN119 which directly participate in the catalytic mechanism of this protein. The proteinligand complex is stabilized mainly by hydrogen bonds and hydrophobic interactions. All the top docked poses generated by each docking routine exhibited wellestablished bonds with one or more amino acids in the binding pocket of $\mathrm{C} 2$-domain of protein kinase $\mathrm{C}$-delta. The top-ranked pose with lowest docked binding affinities and high docking scores is generally used as a standard selection in most of the docking programs. The best poses of C2-domain of protein kinase C-delta-
Rott were generated by AutoDock-Vina. The binding affinity for Rott was found to be $-7.5 \mathrm{Kcal} / \mathrm{mol}$. The orientation and hydrogen bonding, ionic interactions of Rott with C2-domain of protein kinase C-delta active site are shown in Figure 8. These docking experiments suggest that Rott can directly bind to protein kinase C-delta.

\section{Discussion}

In this study we demonstrated that Rott induces early autophagy as a survival strategy against late apoptosis through AMPK and Akt/mTOR cascade dependent pathways in human breast CSCs. One of the most surprising events in the early stage apoptosis by Rott treatment was the cytoplasmic vacuolation. These vacuoles were formed by Rott-induced autophagy and were identified by electron microscopy, acidic vesicular organelle staining, and transfection of green fluorescent protein-LC3. Interestingly, Rott-treated cells did not undergo cell death at $24 \mathrm{~h}$, while at late time points $(72 \mathrm{~h})$ showed significant cell death. Rott induced autophagy at 24-48 h, as evident by formation of autophagosomes and conversion of LC3-I to LC3-II form. Rott was found to cause typical autophagy characteristics, including formation of autophagosomes and acidic vacuoles, and redistribution of LC3 at 24-48 h. These results indicate that treatment with Rott may induce autophagy at an early stage in breast CSCs. Our study for the first time demonstrates that Rott treatment induces autophagy in breast CSCs by activating AMPK pathway.

Autophagy is a catabolic process during which damaged organelles and proteins are engulfed and degraded to provide metabolic needs. Autophagy is activated in response to various kinds of stress. It is a conserved dynamic process in which intracellular membrane structures sequester proteins and organelles, which are finally delivered to lysosomes for bulk degradation and ATP generation to maintain basal cellular bioenergetics [17]. Whereas the above situations envision autophagy as a survival mechanism, autophagy can also lead to cell death under some circumstances [52]. Rott-induced apoptotic cell death was mediated through a decrease of mitochondrial membrane potential and translocation of AIF into nucleus at a late time point. Moreover, the inhibition of Rott-induced autophagy with Baf, 3-MA or CHX slows down apoptotic cell death. The most novel mechanistic aspect of this study is, perhaps, that Rott-induced autophagy may act as a survival factor against caspase-independent cell death. Treatment with Rott induced a dose- and time-dependent growth inhibition and also triggered cell death with cytoplasmic vacuolation in breast CSCs, which is consistent with the reported biological events caused by Rott in breast tumor and malignant glioma cells [53,54]. On the other hand, Rott treatment in the presence of Baf, 3-MA or CHX lead to decreased expression of LC3 when compared to the cells treated either with Rott or inhibitors alone, suggesting 


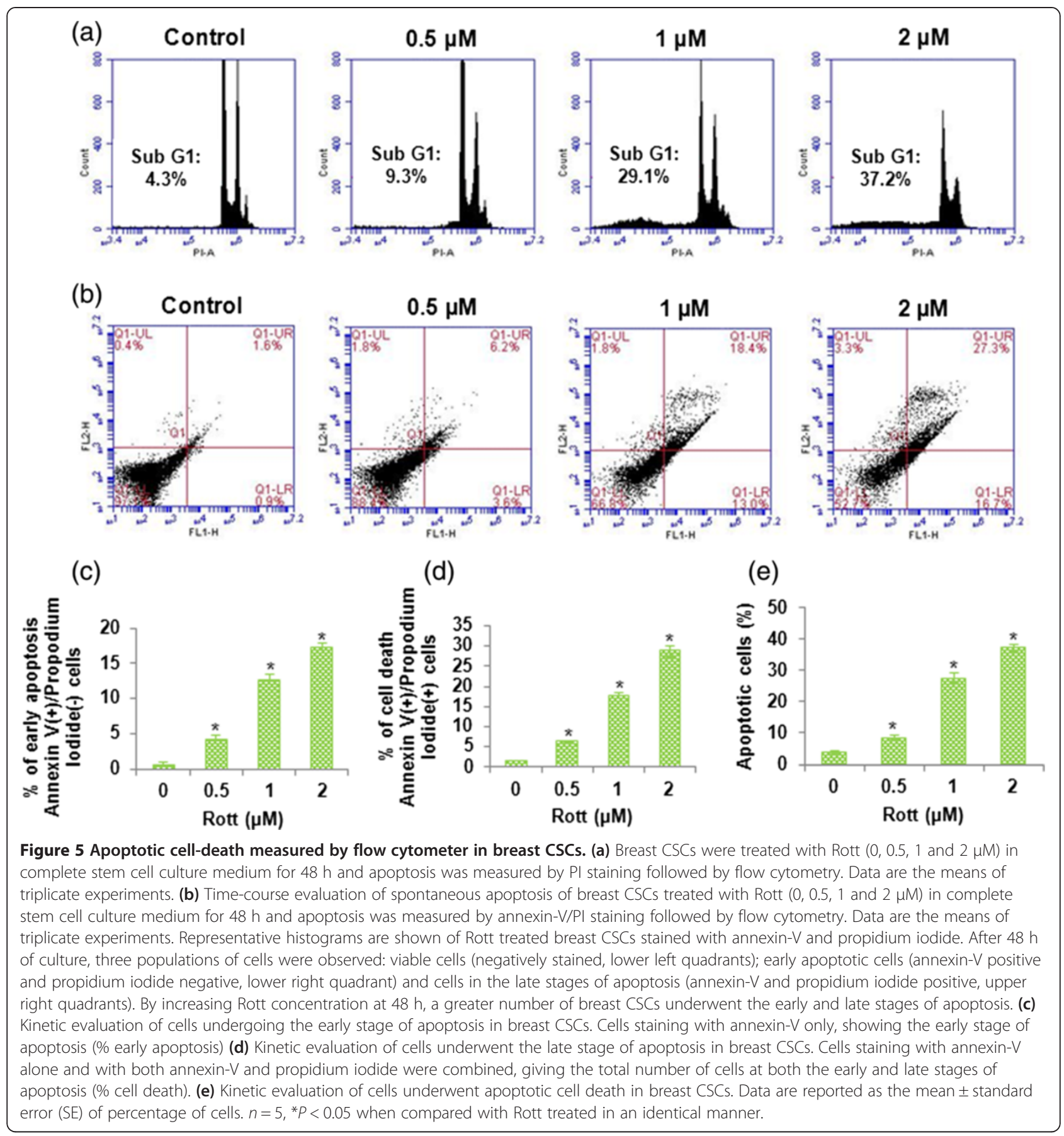

increased autophagic potentials. All three Baf, 3-MA, and $\mathrm{CHX}$ inhibit the fusion between autophagosomes and lysosomes, thus prevent the execution step of autophagy. Nonetheless, our results from flowcytometry demonstrated that autophagy inhibitors (Baf and 3$\mathrm{MA}$ ), and protein synthesis inhibitor (CHX) inhibits Rott-induced autophagy. Our observations are in agreement with several studies demonstrating the role of LC3 in autophagy $[33,55,56]$.
In this study, Rott was found to induce autophagy in breast CSCs, including formation of autophagosomes, redistribution of LC3 and induction of autophagy related proteins including Atg12 and Beclin-1 at 24-48 h. The antiapoptotic protein, $\mathrm{Bcl}-2$, inhibits the Beclin-1 dependent autophagy $[57,58]$. Rott significantly inhibited Bcl-2 and Bcl-xL expression, and induced Atg12 and Beclin-1. Furthermore, Baf, 3-MA or CHX inhibited Rott-induced conversion of LC3-I to LC3-II, and 


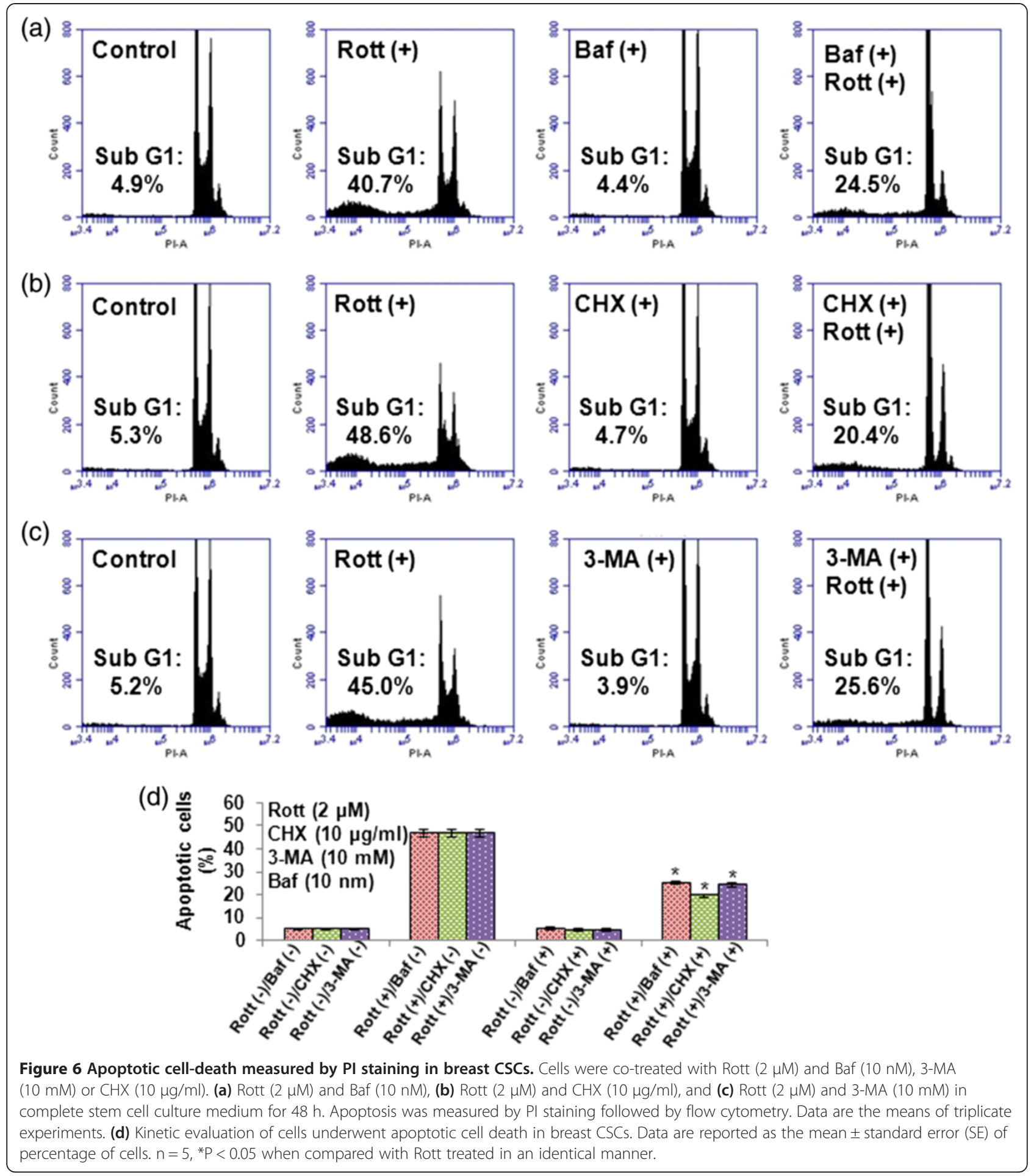

expression of autophagy-related proteins Atg12 and Beclin-1 at 24-48 h. Activation of autophagy by Rott in our model was confirmed by enhanced expression of LC3. Our results also showed that autophagy induction was associated with an increase in the expression of Beclin-1 and Atg12. Autophagy marker LC3 is a protein that is selectively incorporated into autophagosome by directly binding to LC3 and hence aggregate during autophagy. Atg12 is instrumental in the autophagic vesicle biogenesis [19]. These results indicate that Rott induces autophagy at an early stage in breast CSCs. Beclin-1 was originally discovered as a $\mathrm{Bcl}-2$ interacting protein and was one of the first human proteins shown to be indispensable for autophagy [59]. Another autophagic gene 


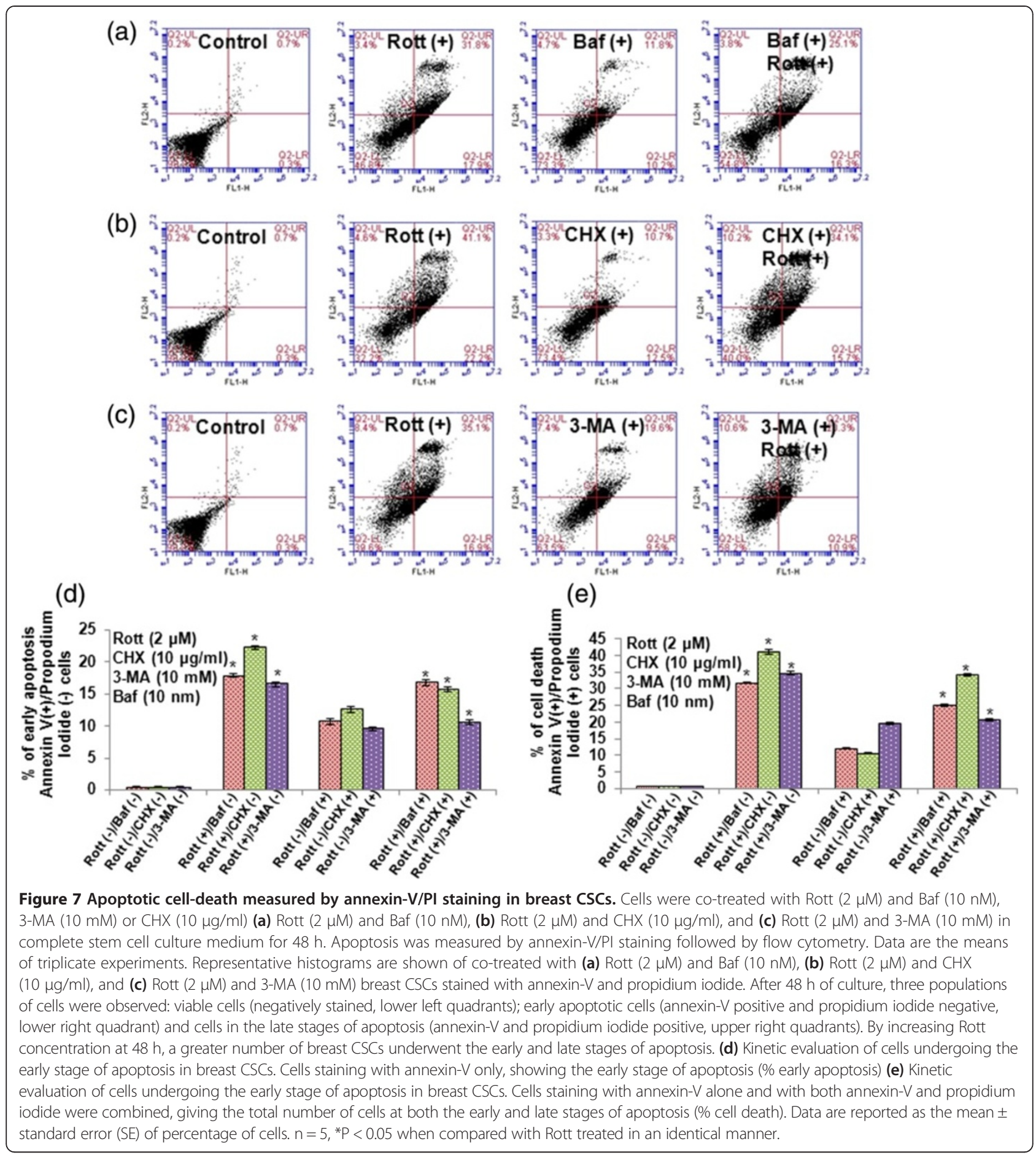

Atg7 is responsible for autophagosome biogenesis [60]. Both genes are monoallelically deleted in $50-75 \%$ of cases of human sporadic breast, ovarian and prostate cancers [60]. Our study demonstrates that co-treatment of the CSCs with Rott and Baf, 3-MA or CHX inhibited the Rott-induced autophagy and slows down the apoptotic process. Therefore, Rott-induced autophagy may play some role in apoptotic cell death. Apoptosis is an important tumor suppressor mechanism that is blocked in the majority of human cancers, due to the over activation of the AMPK and Akt/mTOR pathway [47]. Activation of AMPK and Akt/mTOR pathway regulates transcription factors which modulate distinct sets of genes involved in cell cycle, apoptosis, oxidative stress 


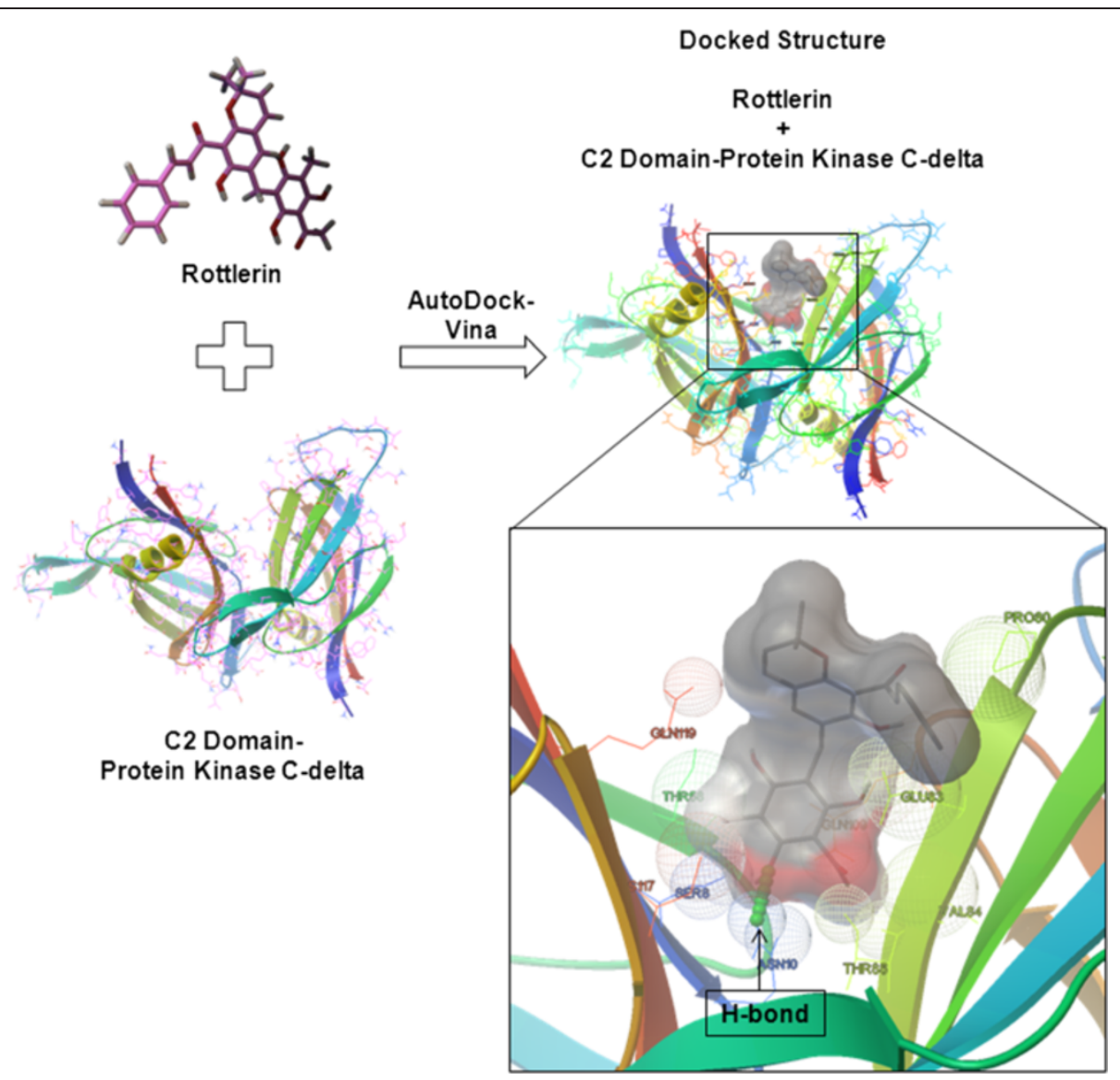

Figure 8 Molecular docking between C2-domain of protein kinase C-delta and rottlerin. Binding conformations of top ranked docked poses of Rott into C2 domain of protein kinase C-delta. Binding activity of docked structure predicted by AutoDock-Vina is only showing important residues are displayed in CPK style. The inhibitors, and part of the amino acid residues in the background were visualized in New Ribbon style using the AutoDockTools4.

and DNA repair [47]. Treatment of CSCs with Rott increased the levels of phosphorylated AMPK. Furthermore, downregulation of constitutively active Akt/mTOR and upregulation of AMPK rendered breast CSCs sensitive to Rott. Rott induced significant apoptosis in breast CSCs at $48 \mathrm{~h}$ by inhibiting phosphorylation of Akt and mTOR, and expression of $\mathrm{Bcl}-2$, Bcl-xL, cIAP1 and XIAP, up-regulation of AMPK and Bax, and activation of caspase-3 and -9. Our results indicate that Rott causes early autophagy and late apoptosis through inhibition of Akt/mTOR pathway in human breast CSCs.

The recent study also suggests that autophagy at early stage may act as a survival mechanism against late apoptosis. Thus, inhibition of autophagy by the potent drugs or genetic means (e.g. inhibiting the expression of Atg7 and Beclin-1) may enhance the apoptosis-inducing potential of Rott in highly therapy-resistant human breast CSCs. Our study established that autophagy induced by Rott treatment was mediated by activation of AMPK pathway. Chemical inhibitors such as Baf, 3-MA or CHX not only blocked the induction of LC3, but also inhibited Rott induced expression of Atg12 in breast CSCs. Rott treatment raises cytosolic calcium levels which activate the various kinases including AMPK which is known to regulate autophagy. AMPK is also an energy sensor and is activated when there is increase in AMP/ ATP ratio, which is usually the scenario during cellular stress, the same reason for which autophagy is activated [33]. In agreement with these facts, Rott treatment activated AMPK in breast CSCs. Baf, 3-MA or CHX not only suppressed Rott induced phosphorylation of AMPK but also attenuated the expression of LC3 and Atg12. All these observations are in agreement with several studies showing that activation of AMPK leads to autophagy [33,45,61].

There are several previous studies has been confirmed that Rott acts as a very effective protein kinase C-delta inhibitor and it plays an essential role in the induction of autophagy and apoptotic cell death $[15,46]$. Apart from studying the effect of Rott on CSCs and the induction of autophagy and apoptotic cell death, we have also studied the computational docking between Rott and C2-domain of protein kinase C-delta. The docking results between 
Rott and C2-domain of protein kinase C-delta generated by AutoDock-Vina showed the strong molecular interactions between Rott and C2-domain of protein kinase C-delta. It forms hydrogen bonds, hydrophobic and ionic interactions with the important residues of the binding pocket of $\mathrm{C} 2$ domain of protein kinase C-delta thus stabilizing the structure of target receptor.

\section{Conclusions}

In the present study, for the first time we conclude that Rott, a natural compound derived from the plant kamala tree (Mallotus philippinensis) with cytotoxic effect, could induce extensive cytoplasmic vacuolization in breast CSCs. The fact that autophagy inhibitors suppress the formation of cytoplasmic vacuolization confirmed that there might be interaction between autophagy and apoptosis induced by Rott. Therefore, Rott could affect the functions of a variety of proteins and act as a multi-target compound. The potency of Rott to induce autophagy and apoptosis at the same dose might be based on its capability to activate several pathways such as AMPK and proteasome inhibition. Further studies are needed to elucidate the complicated signal cascades induced by Rott.

\section{Methods}

\section{Cell culture, reagents and antibodies}

Human breast CSCs [CD44(+)/CD24(-/low)] were isolated from primary tumors and grown in M171 medium (Invitrogen, Carlsbad, CA) containing mammary epithelial growth supplement (MEGS) (Invitrogen, Carlsbad, CA) and $1 \%$ antibiotic-antimycotic (Invitrogen), and maintained in a humidified incubator with $5 \% \mathrm{CO}_{2}$, and $37^{\circ} \mathrm{C}$ temperature. Rott, 3-MA, CHX, Baf, puromycin were obtained from Sigma-Aldrich Corp. (St. Louis, MO). Antihuman LC3, Atg7, Atg12, Beclin-1, Bax, Bcl-2, Bcl-XL, cIAP-1, Akt, pAkt, mTOR, p-mTOR and XIAP, AMPK, pAMPK and $\beta$-actin antibodies were obtained from Cell Signaling Technology (Danvers, MA).

\section{pEGFP-LC3 transfection in breast CSCs}

Breast CSCs were transfected with pEGFP-LC3 plasmid using neon electroporator at $1400 \mathrm{~V}, 2$-pulses for $20 \mathrm{~ms}$. $30 \mu \mathrm{g}$ of DNA was mixed with the cell suspension and electroporated by using $100 \mu \mathrm{l}$ neon tips. After electroporation, pEGFP-LC3 transfected breast CSCs were seeded in $60 \mathrm{~mm}$ culture dish. After 2 days, transfected cells were selected by $10 \mu \mathrm{M}$ neomycin, and visualized under Leica 6000B microscope with 10X objectives.

\section{Lentiviral particle production and Atg7 and Beclin-1 transduction}

Atg7 shRNA and Beclin-1 shRNA were obtained from Open Biosystems (Lafayette, CO). Lentivirus particles were produced by triple transfection of HEK 293 T cells.
Packaging 293 T cells were plated in $10 \mathrm{~cm}$ plates at a cell density of $5 \times 10^{6}$. Transfection of packaging cells and infection of breast CSCs were carried out using standard protocols with some modifications. In brief, $293 \mathrm{~T}$ cells were transfected with $8 \mathrm{mg}$ of plasmid and $4 \mathrm{mg}$ of lentiviral vector using lipid transfection (Lipofectamine-2000) according to the manufacturer's protocol. Viral supernatants were collected and concentrated by adding PEG-it virus precipitation solution (SBI System Biosciences, Mountain View, CA). Breast CSCs were transduced with viral particles expressing scrambled, Atg7 shRNA or Beclin-1 shRNA.

\section{Vacuolated cell enumeration}

Cells were seeded in 6-well plates at a density of $1 \times 10^{4}$ cells/well in complete stem cell culture medium and incubated overnight. Cells were then treated with various concentration of Rott $(0,0.5,1$ and $2 \mu \mathrm{M})$ for $48 \mathrm{~h}$. Vacuolated cells were counted using fluorescent microscope in at least 100 cells for each condition.

\section{Immunofluorescence assay}

Cells were grown on fibronectin-coated coverslips (Beckton Dickinson, Bedford, MA), and treated with Rott (0, 0.5, 1 and $2 \mu \mathrm{M}$ ), washed in PBS, and fixed for $15 \mathrm{~min}$ in $4 \%$ paraformaldehyde. Cells were permeabilized in $0.1 \%$ Triton $\mathrm{X}-100$, washed and blocked in 10\% normal goat serum. After blocking, cells were incubated with primary antibody (1:100) for overnight at $4^{\circ} \mathrm{C}$, washed with PBS and incubated with fluorescently labeled secondary antibody (1:200) along with 4, 6-diamido-2-phenylindole hydrochloride (DAPI) $(1 \mathrm{mg} / \mathrm{ml})$ for $1 \mathrm{~h}$ at room temperature. Finally, coverslips were washed and mounted using vectashield (Vector Laboratories, Burlington, CA). Isotype-specific negative controls were included with each staining. Stained cells were mounted and visualized under Leica 6000B microscope with 100X objectives. The number of cells expressing punctate and the number of punctate per cell were counted manually.

\section{Nuclear staining with DAPI}

After Rott treatment, adherent cells were fixed for $20 \mathrm{~min}$ at room temperature with $4 \%$ paraformaldehyde and permeablized for $10 \mathrm{~min}$ with $0.2 \%$ Triton X-100 in PBS. After PBS washes, cells were stained with 4, 6-diamido-2phenylindole hydrochloride (DAPI) in PBS at the concentration of $1 \mathrm{mg} / \mathrm{ml}$ for $15 \mathrm{~min}$ at room temperature. Cells were then washed with PBS and visualized using Leica 6000B microscope with 100X objectives.

\section{$\mathrm{XTT}$ based cell viability assay}

Breast CSCs $\left(1 \times 10^{4}\right.$ in $200 \mu \mathrm{l}$ culture medium per well) were seeded in 96-well plate (flat bottom), treated with Rott $(0,0.5,1$ and $2 \mu \mathrm{M})$, and incubated for $48 \mathrm{~h}$ at $37^{\circ} \mathrm{C}$ with $5 \% \mathrm{CO}_{2}$. Before the end of the experiment, $50 \mu \mathrm{l} \mathrm{XTT}$ 
labeling mixture (final concentration, $125 \mu \mathrm{M}$ XTT (sodium 2,3-Bis(2-methoxy-4-nitro-5-sulfophenyl)-2H-tetrazolium-5-carboxanilide inner salt) and $25 \mu \mathrm{M}$ PMS (phenazine methosulphate) per well was added and plates were incubated for further $4 \mathrm{~h}$ at $37^{\circ} \mathrm{C}$ and $5 \% \mathrm{CO}_{2}$. The spectrophotometric absorbance of the sample was measured using a microtitre plate (ELISA) reader. The wavelength to measure absorbance of the formazon product was $450 \mathrm{~nm}$, and the reference wavelength was $650 \mathrm{~nm}$.

\section{Measurement of apoptotic cell death by flow cytometer}

Breast CSCs (10000 cells/well) were seeded in 6 well plate and exposed to Rott $(0,0.5,1$ and $2 \mu \mathrm{M})$. Cells were then washed in PBS and collected by trypsinization, and fixed overnight in $70 \%$ glacial ethanol. Next day cells were washed in PBS and resuspended in $1 \mathrm{~mL}$ of PBS containing $50 \mu \mathrm{g} / \mathrm{mL}$ RNase and incubated at $37^{\circ} \mathrm{C}$ for $2 \mathrm{~h} .50 \mu \mathrm{g} / \mathrm{mL}$ propidium iodide (PI) added in resuspended cells and then incubated for $60 \mathrm{~min}$ in dark at $4^{\circ} \mathrm{C}$. Cell cycle analysis was performed by flow cytometry (Becton Dickinson, Franklin Lakes, NJ, USA), and the population of cells in each phase was calculated using the Cell Quest software program. Each experiment was conducted three times.

Breast CSCs (10000 cells/well) were seeded in 6-well plates and exposed to Rott $(0,0.5,1$ and $2 \mu \mathrm{M})$. Treated cells were washed twice with cold PBS and resuspended in buffer at a concentration of $10^{6}$ cells per ml. Cells were mixed with $10 \mu \mathrm{l}$ of fluoresceine isothiocyanate (FITC)-conjugated annexin-V reagent and $10 \mu \mathrm{l}$ of $3 \mathrm{mM}$ propidium iodide (PI). After $15 \mathrm{~min}$ incubation at room temperature in the dark and further washings, samples were analyzed by flow cytometry. Flow cytometry was performed with a FACScan analyzer (Becton Dickinson, Franklin Lakes, NJ, USA) with15 mW argon ion laser $(488 \mathrm{~nm})$ and Cell Quest software. Annexin-V staining was detected in the FL1 channel, whereas PI staining was monitored in the FL2 channel: appropriate quadrants were set and the percentage of cells negative for stains (viable cells), positive for annexin-V (apoptotic cells) and positive for PI (dead cells) were acquired.

\section{Electron microscopy}

To demonstrate the induction of autophagy in Rotttreated breast CSCs, cells were treated with $(0,0.5,1$ and $2 \mu \mathrm{M}$ ) of Rott for $24 \mathrm{~h}$; cells were harvested by trypsinization, washed and fixed in $2 \%$ glutaraldehyde in $0.1 \mathrm{M}$ phosphate buffer, then post-fixed in $1 \%$ osmium tetroxide buffer. After dehydration in a graded series of ethanol, cells were embedded in spur resin. Thin sections $(60 \mathrm{~nm})$ were cut on an Ultramicrotome. The sectioned grids were stained with saturated solutions of uranyl acetate and lead citrate. The sections were examined by electron microscope.

\section{Preparation of whole-cell lysates}

After treatment with Rott $(0,0.5,1$ and $2 \mu \mathrm{M})$, breast CSCs were pelleted by centrifugation at $1,000 \mathrm{X}$ rpm for $5 \mathrm{~min}$ and washed once with PBS. Cells were then resuspended in RIPA buffer (50 mM Tris- $\mathrm{HCl}, \mathrm{pH} 7.5,150 \mathrm{mM} \mathrm{NaCl}$, $1 \% \mathrm{v} / \mathrm{v}$ Nonidet P-40, 0.5\% v/v sodium deoxycholate and $0.1 \%$ SDS) supplemented with protease inhibitor cocktail (Sigma) and phosphatase inhibitor cocktail (Sigma), and lysed on ice by sonicating for $5 \mathrm{~s}$ and 5-10 pulses. The lysates were centrifuged for $20 \mathrm{~min}$ at 12,000 X g and supernatant was collected and used for further experiments.

\section{Western blot analysis}

Total cellular lysates were obtained by lysing cells in a buffer containing RIPA buffer and a mixture of protease and phosphatase inhibitors. Lysates were sonicated for $5 \mathrm{~s}$ and 5-10 pulses, centrifuged for $20 \mathrm{~min}$ at 12,000 X $\mathrm{g}$ and stored at $-80^{\circ} \mathrm{C}$. Equal amounts of lysate proteins (50-60 $\mu \mathrm{g}$ total protein) were electrophoretically separated by $10 \%$ sodium dodecyl sulfate-polyacrylamide gel electrophoresis (SDS-PAGE) and transferred to nitrocellulose membrane. Nitrocellulose blots were blocked with $5 \%$ nonfat dry milk in TBS buffer $(20 \mathrm{mM}$ Tris- $\mathrm{HCl}$, $\mathrm{pH} 7.4$, and $500 \mathrm{mM} \mathrm{NaCl}$ ), and incubated with primary antibody in TBS-T (TBS and $0.01 \%$ Tween-20) overnight at $4^{\circ} \mathrm{C}$. Immunoblots were washed three times (5, 5 and 5 min each) with TBS-T followed by $1-2 \mathrm{~h}$ incubation with secondary antibody. Chemiluminescence reactions were carried out with the Super Signal West Pico substrate (Thermo Fisher, Waltham, MA).

\section{AutoDock-Vina docking file preparation and running docking program}

Ligands (Rott) were designed by using ACD/ChemSketch Freeware software (http://www.acdlabs.com/resources/freeware/chems- ketch/). Open Babel (An open chemical toolbox) software used to convert 3D structure of ligand (.MOL file) into.PDB file. Ligands were optimized by using Graphical User Interface program AutoDockTools4 (ADT) [62]. Protein (C2-domain of protein kinase C-delta) was downloaded from RCSBProtein Data Bank (PDB-ID: 1BDY) [49] and edited in.txt file. Protein was optimized by using ADT [62]. Intermediary steps, such as.pdbqt files for protein and ligands preparation and grid box creation were completed using ADT. ADT assigned charges, solvation parameters and fragmental volumes to the protein. AutoDock saved the prepared file in pdbqt format. AutoGrid was used for the preparation of the grid map using a grid box. The grid size was set to $58 \times 56 \times 74$ xyz points with grid spacing of $0.375 \AA$ and grid center was designated at dimensions (x, y, and $\mathrm{z})$ : -3.085, 28.517 and 37.651. AutoDock-Vina was employed for docking using protein and ligand information along with grid box properties in the 
configuration file. AutoDock-Vina employs iterated local search global optimizer [50]. During the docking procedure, both the protein and ligands are considered as rigid. The results less than $1.0 \AA$ in positional root-mean-square deviation (RMSD) was clustered together and represented by the result with the most favorable free energy of binding. The pose with lowest energy of binding or binding affinity was extracted and aligned with receptor structure for further analysis.

\section{Abbreviations \\ 3-MA: 3-Methyladenine; AMPK: Adenosine monophosphate-activated protein kinase; Baf: Bafilomycin; CSCs: Cancer stem cells; CHX: Cycloheximide; Rott: Rottlerin; XTT: (sodium 2,3-Bis(2-methoxy-4- nitro-5-sulfophenyl)-2H-tetrazolium-5-carboxanilide inner salt).}

\section{Competing interests}

The authors declare no competing interests.

\section{Authors' contributions}

DK conceived the idea, performed the experiments and analyzed the data; SS and RK designed the experiments; DK wrote the manuscript. All authors read and approved the manuscript

\section{Acknowledgements}

We thank our lab members for critical reading of the manuscript.

\section{Author details}

'Department of Pharmacology, Toxicology and Therapeutics, and Internal Medicine, The University of Kansas Medical Center, 3901 Rainbow Boulevard, Kansas City, KS 66160, USA. ²Department of Pathology and Laboratory Medicine, The University of Kansas Medical Center, 3901 Rainbow Boulevard, Kansas City, KS 66160, USA

Received: 23 August 2013 Accepted: 7 December 2013

Published: 23 December 2013

\section{References}

1. Yue ZY, Jin SK, Yang CW, Levine AJ, Heintz N: Beclin 1, an autophagy gene essential for early embryonic development, is a haploinsufficient tumor suppressor. Proc Natl Acad Sci USA 2003, 100:15077-15082.

2. Deretic V, Delgado M, Vergne I, Master S, De Haro S, Ponpuak M, Singh S: Autophagy in Immunity against mycobacterium tuberculosis: a model system to dissect immunological roles of autophagy. Autophagy 2009, 335:169-188.

3. Klionsky DJ, Emr SD: Cell biology - Autophagy as a regulated pathway of cellular degradation. Science 2000, 290:1717-1721.

4. Maiuri MC, Zalckvar E, Kimchi A, Kroemer G: Self-eating and self-killing: crosstalk between autophagy and apoptosis. Nat Rev Mol Cell Biol 2007, 8:741-752.

5. Levine B, Kroemer G: Autophagy in the pathogenesis of disease. Cell 2008, 132:27-42.

6. Talloczy Z, Jiang WX, Virgin HW, Leib DA, Scheuner D, Kaufman RJ, Eskelinen EL, Levine B: Regulation of starvation- and virus-induced autophagy by the elF2 alpha kinase signaling pathway. Proc Natl Acad Sci U S A 2002, 99:190-195.

7. Kanzawa T, Germano IM, Komata T, Ito H, Kondo Y, Kondo S: Role of autophagy in temozolomide-induced cytotoxicity for malignant glioma cells. Cell Death Differ 2004, 11:448-457.

8. Kanzawa T, Kondo Y, Ito H, Kondo S, Germano I: Induction of autophagic cell death in malignant glioma cells by arsenic trioxide. Cancer Res 2003, 63:2103-2108

9. Paglin S, Hollister T, Delohery T, Hackett N, McMahill M, Sphicas E, Domingo D, Yahalom J: A novel response of cancer cells to radiation involves autophagy and formation of acidic vesicles. Cancer Res 2001, 61:439-444.

10. Lum JJ, Bauer DE, Kong M, Harris MH, Li C, Lindsten T, Thompson CB: Growth factor regulation of autophagy and cell survival in the absence of apoptosis. Cell 2005, 120:237-248.
11. Onodera J, Ohsumi $Y$ : Autophagy is required for maintenance of amino acid levels and protein synthesis under nitrogen starvation. $J$ Biol Chem 2005, 280:31582-31586.

12. Baehrecke EH: Autophagy: dual roles in life and death? Nat Rev Mol Cell Biol 2005, 6:505-510.

13. Livesey KM, Tang DL, Zeh HJ, Lotze MT: Autophagy inhibition in combination cancer treatment. Curr Opin Investig Drugs 2009, 10:1269-1279.

14. Taguchi-Atarashi N, Hamasaki M, Matsunaga K, Omori H, Ktistakis NT, Yoshimori T, Noda T: Modulation of Local Ptdlns3P Levels by the PI Phosphatase MTMR3 Regulates Constitutive Autophagy. Traffic 2010, 11:468-478.

15. Singh BNKD, Shankar S, Srivastava RK: Rottlerin induces autophagy which leads to apoptotic cell death through inhibition of PI3K/Akt/mTOR pathway in human pancreatic cancer stem cells. Biochem Pharmacol 2012, 84(9):1154-1163.

16. Kumar D, Shankar S, Srivastava RK: Rottlerin induces autophagy and apoptosis in prostate cancer stem cells via PI3K/Akt/mTOR signaling pathway. Cancer Lett 2013, S0304-3835(13):00714-00723.

17. Levine B, Yuan J: Autophagy in cell death: an innocent convict? J Clin Invest 2005, 115:2679-2688

18. Geng JF, Baba M, Nair U, Klionsky DJ: Quantitative analysis of autophagyrelated protein stoichiometry by fluorescence microscopy (vol 182, pg 129, 2008). J Cell Biol 2008, 183:1175-1175.

19. Gozuacik D, Kimchi A: Autophagy as a cell death and tumor suppressor mechanism. Oncogene 2004, 23:2891-2906.

20. Nemoto T, Tanida I, Tanida-Miyake E, Minematsu-lkeguchi N, Yokota M, Ohsumi M, Ueno T, Kominami E: The mouse APG10 homologue, an E2-like enzyme for Apg12p conjugation, facilitates MAP-LC3 modification. J Biol Chem 2003, 278:39517-39526.

21. Mizushima N, Yamamoto A, Hatano M, Kobayashi Y, Kabeya Y, Suzuki K, Tokuhisa T, Ohsumi Y, Yoshimori T: Dissection of autophagosome formation using Apg5-deficient mouse embryonic stem cells. J Cell Biol 2001, 152:657-667.

22. Kourtis N, Tavernarakis N: Autophagy and cell death in model organisms. Cell Death Differ 2009, 16:21-30

23. Qu XP, Yu J, Bhagat G, Furuya N, Hibshoosh H, Troxel A, Rosen J, Eskelinen EL, Mizushima N, Ohsumi Y, et al: Promotion of tumorigenesis by heterozygous disruption of the beclin 1 autophagy gene. J Clin Invest 2003, 112:1809-1820.

24. Batrakova EV, Gendelman HE, Kabanov AV: Cell-mediated drug delivery. Expert Opin Drug Deliv 2011, 8:415-433.

25. Martelli AM, Evangelisti C, Follo MY, Ramazzotti G, Fini M, Giardino R, Manzoli L, McCubrey JA, Cocco L: Targeting the Phosphatidylinositol 3-Kinase/Akt/Mammalian Target of Rapamycin Signaling Network in Cancer Stem Cells. Curr Med Chem 2011, 18:2715-2726.

26. Singh BN, Kumar D, Shankar S, Srivastava RK: Rottlerin induces autophagy which leads to apoptotic cell death through inhibition of PI3K/Akt/mTOR pathway in human pancreatic cancer stem cells. Biochem Pharmacol 2012, 84:1154-1163

27. Shao Y, Gao Z, Marks PA, Jiang X: Apoptotic and autophagic cell death induced by histone deacetylase inhibitors. Proc Natl Acad Sci USA 2004, 101:18030-18035.

28. Gonzalez-Polo RA, Niso-Santano M, Ortiz-Ortiz MA, Gomez-Martin A, Moran JM, Garcia-Rubio L, Francisco-Morcillo J, Zaragoza C, Soler G, Fuentes JM: Inhibition of paraquat-induced autophagy accelerates the apoptotic cell death in neuroblastoma SH-SY5Y cells. Toxicol Sci 2007, 97:448-458.

29. Herman-Antosiewicz A, Johnson DE, Singh SV: Sulforaphane causes autophagy to inhibit release of cytochrome $C$ and apoptosis in human prostate cancer cells. Cancer Res 2006, 66:5828-5835.

30. Nguyen TM, Subramanian IV, Kelekar A, Ramakrishnan S: Kringle 5 of human plasminogen, an angiogenesis inhibitor, induces both autophagy and apoptotic death in endothelial cells. Blood 2007, 109:4793-4802

31. Boya P, Gonzalez-Polo RA, Casares N, Perfettini JL, Dessen P, Larochette N, Metivier D, Meley D, Souquere S, Yoshimori T, et al: Inhibition of macroautophagy triggers apoptosis. Mol Cell Biol 2005, 25:1025-1040.

32. Luo S, Rubinsztein DC: Atg5 and Bcl-2 provide novel insights into the interplay between apoptosis and autophagy. Cell Death Differ 2007, 14:1247-1250.

33. Kandala PK, Srivastava SK: Regulation of macroautophagy in ovarian cancer cells in vitro and in vivo by controlling glucose regulatory protein 78 and AMPK. Oncotarget 2012, 3:435-449. 
34. Jia L, Dourmashkin RR, Allen PD, Gray AB, Newland AC, Kelsey SM: Inhibition of autophagy abrogates tumour necrosis factor alpha induced apoptosis in human T-lymphoblastic leukaemic cells. Br J Haematol 1997, 98:673-685

35. Espert L, Denizot M, Grimaldi M, Robert-Hebmann V, Gay B, Varbanov M, Codogno P, Biard-Piechaczyk M: Autophagy is involved in T cell death after binding of HIV-1 envelope proteins to CXCR4. J Clin Invest 2006, 116:2161-2172.

36. Amaravadi RK, Yu DN, Lum JJ, Bui T, Christophorou MA, Evan Gl, Thomas-Tikhonenko A, Thompson CB: Autophagy inhibition enhances therapy-induced apoptosis in a Myc-induced model of lymphoma. J Clin Invest 2007, 117:326-336.

37. Kroemer G, Marino G, Levine B: Autophagy and the Integrated Stress Response. Mol Cell 2010, 40:280-293.

38. Xu CY, Bailly-Maitre B, Reed JC: Endoplasmic reticulum stress: cell life and death decisions. J Clin Invest 2005, 115:2656-2664

39. Denmeade SR, Isaacs JT: The SERCA pump as a therapeutic target Making a "smart bomb" for prostate cancer. Cancer Biol Ther 2005, 4:14-22.

40. Hoyer-Hansen M, Jaattela M: Connecting endoplasmic reticulum stress to autophagy by unfolded protein response and calcium. Cell Death Differ 2007, 14:1576-1582.

41. Hoyer-Hansen M, Bastholm L, Szyniarowski P, Campanella M, Szabadkai G, Farkas T, Bianchi K, Fehrenbacher N, Elling F, Rizzuto R, et al: Control of macroautophagy by calcium, calmodulin-dependent kinase kinase-beta, and Bcl-2. Mol Cell 2007, 25:193-205.

42. Demarchi F, Bertoli C, Copetti T, Tanida I, Brancolini C, Eskelinen EL, Schneider C: Calpain is required for macroautophagy in mammalian cells. J Cell Biol 2006, 175:595-605.

43. Green MF, Anderson KA, Means AR: Characterization of the CaMKKß-AMPK signaling complex. Cell Signal 2011, 23(12):2005-2012.

44. Kim J, Kundu M, Viollet B, Guan KL: AMPK and mTOR regulate autophagy through direct phosphorylation of Ulk1. Nat Cell Biol 2011, 13:132-U171.

45. Egan DF, Shackelford DB, Mihaylova MM, Gelino S, Kohnz RA, Mair W, Vasquez DS, Joshi A, Gwinn DM, Taylor R, et al: Phosphorylation of ULK1 (hATG1) by AMP-Activated Protein Kinase Connects Energy Sensing to Mitophagy. Science 2011, 331:456-461.

46. Gschwendt M, Muller HJ, Kielbassa K, Zang R, Kittstein W, Rincke G, Marks F: Rottlerin, a Novel Protein-Kinase Inhibitor. Biochem Biophys Res Commun 1994, 199:93-98.

47. Saiki S, Sasazawa Y, Imamichi Y, Kawajiri S, Fujimaki T, Tanida I, Kobayashi H, Sato F, Sato S, Ishikawa Kl, et al: Caffeine induces apoptosis by enhancement of autophagy via PI3K/Akt/mTOR/p70S6K inhibition. Autophagy 2011, 7:176-187.

48. Shankar S, Nall D, Tang SN, Meeker D, Passarini J, Sharma J, Srivastava RK Resveratrol inhibits pancreatic cancer stem cell characteristics in human and kras(G12D) transgenic mice by inhibiting pluripotency maintaining factors and epithelial-mesenchymal transition. PLOS One 2011 6(1):e16530.

49. Pappa H, Murray-Rust J, Dekker LV, Parker PJ, McDonald NQ: Crystal structure of the C2 domain from protein kinase C-delta. Structure 1998, 6:885-894

50. Trott O, Olson AJ: AutoDock Vina: improving the speed and accuracy of docking with a new scoring function, efficient optimization, and multithreading. J Comput Chem 2010, 31:455-461.

51. Azam SS, Abbasi SW: Molecular docking studies for the identification of novel melatoninergic inhibitors for acetylserotonin-O-methyltransferase using different docking routines. Theor Biol Med Model 2013, 10:63.

52. Kessel D, Reiners JJ, Hazeldine ST, Polin L, Horwitz JP: The role of autophagy in the death of L1210 leukemia cells initiated by the new antitumor agents, XK469 and SH80. Mol Cancer Ther 2007, 6:370-379.

53. Basu A: Involvement of protein kinase C-delta in DNA damage-induced apoptosis. J Cell Mol Med 2003, 7:341-350.

54. Zhivotovsky B, Samali A, Gahm A, Orrenius S: Caspases: their intracellular localization and translocation during apoptosis. Cell Death Differ 1999, 6:644-651.

55. Puissant A, Robert G, Fenouille N, Luciano F, Cassuto JP, Raynaud S, Auberger P: Resveratrol promotes autophagic cell death in chronic myelogenous leukemia cells via JNK-mediated p62/SQSTM1 expression and AMPK activation. Cancer Res 2010, 70(3):1042-1052
56. Lee YJ, Kim NY, Suh YA, Lee C: Involvement of ROS in Curcumin-induced Autophagic Cell Death. Korean J Physiol Pharmacol 2011, 15(1):1-7.

57. Gaytán M, Morales C, Sánchez-Criado JE, Gaytán F: Immunolocalization of beclin 1, a bcl-2-binding, autophagy-related protein, in the human ovary: possible relation to life span of corpus luteum. Cell Tissue Res 2008, 331(2):509-517.

58. Pattingre S, Tassa A, Qu X, Garuti R, Liang XH, Mizushima N, Packer M, Schneider MD, Levine B: Bcl-2 antiapoptotic proteins inhibit Beclin 1-dependent autophagy. Cell 2005, 122:927-939.

59. Liang XH, Jackson S, Seaman M, Brown K, Kempkes B, Hibshoosh H, Levine $\mathrm{B}$ : Induction of autophagy and inhibition of tumorigenesis by beclin 1 . Nature 1999, 402:672-676.

60. Sun WL, Chen J, Wang YP, Zheng H: Autophagy protects breast cancer cells from epirubicin-induced apoptosis and facilitates epirubicin-resistance development. Autophagy 2011, 7:1035-1044.

61. Yang PM, Liu YL, Lin YC, Shun CT, Wu MS, Chen CC: Inhibition of autophagy enhances anticancer effects of atorvastatin in digestive malignancies. Cancer Res 2010, 70(19):7699-7709.

62. Morris GM, Huey R, Lindstrom W, Sanner MF, Belew RK, Goodsell DS, Olson AJ: AutoDock4 and AutoDockTools4: automated docking with selective receptor flexibility. J Comput Chem 2009, 30:2785-2791.

\section{doi:10.1186/1476-4598-12-171}

Cite this article as: Kumar et al:: Rottlerin-induced autophagy leads to the apoptosis in breast cancer stem cells: molecular mechanisms. Molecular Cancer 2013 12:171.

\section{Submit your next manuscript to BioMed Central and take full advantage of:}

- Convenient online submission

- Thorough peer review

- No space constraints or color figure charges

- Immediate publication on acceptance

- Inclusion in PubMed, CAS, Scopus and Google Scholar

- Research which is freely available for redistribution 